\title{
The power of human cytomegalovirus (HCMV) hijacked UL/b' functions lost in vitro
}

\author{
V. KEMPOVÁ ${ }^{1}$, S. LENHARTOVÁ ${ }^{1}$, M. BENKO ${ }^{1}$, M. NEMČOVIČ ${ }^{2}$, M. KÚDELOVÁ ${ }^{1}$, I. NEMČOVIČOVÁ $^{1 *}$
}

\begin{abstract}
${ }^{1}$ Institute of Virology, Biomedical Research Center Slovak Academy of Sciences, Dúbravská cesta 9, 84505 Bratislava,
\end{abstract} Slovak Republic; ${ }^{2}$ Institute of Chemistry, Slovak Academy of Sciences, Bratislava, Slovak Republic

\begin{abstract}
Summary. - Viruses have evolved sophisticated strategies to subvert immunity to benefit overall viral fitness. Human cytomegalovirus (HCMV, $\beta$-herpesvirus) represents a paradigm of very effective hijacking of gene functions that imitate host encoded immunomodulatory proteins. This co-evolution with the host immune system allowed for establishment of lifelong persistence. The HCMV infection is largely asymptomatic in healthy persons; however, it can induce serious disease in immunocompromised individuals. For this reason, great attention is paid to the development of therapeutics based on HCMV immunomodulatory 'tricks' as well as to the search for active vaccine against HCMV. While comparing the HCMV clinical isolates with extensively passaged laboratory strains, the unique long (UL) b' locus was commonly found to be deleted in HCMV genome while adapted to replication in human fibroblasts in vitro. This missing region, called UL/b' region, encodes up to 22 canonical genes with different functions, as of targeting cellular tropism (e.g. UL133-UL138); viral entry and assembly (e.g. UL128, UL130, UL131A); regulation of immunological synapses (e.g. UL135); inhibition of NK and T cell function (e.g. UL141, UL142, UL148, UL144), ablating activity (e.g. UL146, UL147), but mainly aimed at manipulating the host immune response. Moreover, the presence of UL/b' genomic region dramatically correlates with adverse effects in vaccinated persons, indicating that viral genes in this region play a significant role in controlling virulence. Here, we review how HCMV shapes our immunity by hijacked genes originated from UL/b' locus, discuss their impact in immunomodulation mechanism and how this knowledge may translate to clinical applications.
\end{abstract}

Keywords: immunomodulation; HCMV genes; UL/b' locus; NK cell function; HCMV vaccine; immunity; immunotherapeutics

*Corresponding author. E-mail: viruivka@savba.sk; phone: +421-2-59302-435.

Abbreviations: $\mathrm{HCMV}=$ human cytomegalovirus, $\beta$-herpesvirus; $\mathrm{UL} / \mathrm{b}^{\prime}=$ unique long $\mathrm{b}^{\prime}$ region; BTLA = B- and T-lymphocyte attenuator; $\mathrm{CD} 155$ = cluster of differentiation 155 , poliovirus receptor/nectin-like molecule 5; CD160 = natural killer cell-activating receptor; $\mathrm{CMV}$ = cytomegalovirus; $\mathrm{CXC}=$ chemokine motif; DNAM-1 = DNAX accessory molecule 1, CD226; ER = endoplasmic reticulum; $\mathrm{gH}$ = glycoprotein $\mathrm{H}$ (gB, gM, gN, gL, gO); HVEM = herpes virus entry mediator; $\mathrm{NK}=$ natural killer; $\mathrm{NKG} 2 \mathrm{D}=\mathrm{NK}$ group 2D; RANTES = regulated on activation, normal T cell expressed and secreted; TB40E = bacterial artificial chromosome (BAC) clones of the HCMV; TIGIT = T cell immunoreceptor with Ig and ITIM domains; TNF = tumor necrosis factor; TRAIL-Rs (1 and 2) = TNF-related apoptosis inducing ligand receptors 1 and 2; vCXCL1 and 2 = viral chemokine homolog 1 and 2; VRPs $=$ viral replicon particles

\section{Introduction}

The immune system and HCMV infection

The immune system is a highly connected network of cells and molecules with specialized roles in defending against infection, as well as a network of many different types of response arranged to maintain status quo of a pathogen-free internal environment (Delves and Roitt, 2000). Leukocytes, the cells of immune system, are divided on the basis of the proteins that are expressed in their cell membranes. Among these proteins are receptors by which cells interact with each other and the environment. Receptors bind ligands that may be receptors on other cells, or soluble molecules such as cytokines. The major role of immune system is to provide protection against the 
various pathogens that are encountered throughout the lifetime of an individual. On the other hand, the immune system has an uneasy relationship with the environment. Pathogens use a variety of ways of attaching and entering the host. For every pathogen, this process is tailored to species, to specific cell types and to defined cell-surface receptors while each infection uses a different cell door. Therefore, blocking these access paths can stop the infection before it starts. In the production of antibodies, the immune system can neutralize infection before the key to the cell turns at that particular doorway. However, this must be done at the same time. An ability of host immune system to adapt flexibly to strange environmental changes is critical in managing infections and cancer. An effective immune system must be able to discriminate such differences, distinguishing self from non-self and distinguishing harmless non-self from dangerous nonself (Nicholson, 2016). This remarkable flexibility and a process of recognition at a near molecular scale allows the immune system to exploit the fact that all organisms are defined by proteins encoded in their genes.

Natural killer (NK) cells play an important role in the control of viral infections, which recognize and eliminate virus-infected cells. Viruses can spend most of their lives hidden in the complicated cytoplasm of a cell, making it difficult to recognize them from the outside. Receptors within the cytoplasm can bind to virus-derived signature molecules, such as different types of nucleic acid and signal that infection is present. Cytomegaloviruses play a major role in formation of current knowledge of how NK cells recognize and destroy virus-infected cells. Disruption of these functions at multiple levels may not only play a role in controlling primary infections or reactivation, but may also affect other immune system functions and leave a long-lasting effect on the NK cell population. These imprints may result in an altered host response to other infections (Lisnić et al., 2015; Nicholson, 2016).

This co-evolutionary relationship between host and pathogen is particularly clear for viruses that establish persistent infections, such as human herpesviruses (HHV)(Šedý et al., 2008). Human cytomegalovirus (HCMV, a $\beta$-herpesvirus, HHV-5), is a large double-stranded DNA virus. This virus causes primary infection through transmission via numerous pathways, such as saliva, breastfeeding, placenta transfer, blood transfusion, solid-organ transplantation and hematopoietic stem cell transplantation. Following primary infection, cytomegalovirus establishes latency with periodic reactivation and shedding from mucosal surfaces. The HCMV contains wide range of immunoevasive genes encoded by the virus which could be a consequence of the inability of the host to prevent this chronic reactivation. Although primary infection rarely causes serious clinical symptoms in healthy adults, opportunistically induces life-threatening disease with long-term sequelae (infectious mononucleosis and splenomegaly) in the immune compromised individuals, such as transplant recipients, Acquired Immune Deficiency Syndrome (AIDS) patients and following infection of the fetus (Mocarski et al., 2013; Orange, 2013; Lisnić et al., 2015).

Except for primary infection or reactivation of the virus in immunosuppressed adults there exists another way by which CMV causes significant morbidity and mortality - congenital infection. Congenital infection is the most common intrauterine infection, and can occur as a result of primary maternal infection, reactivation of latent virus or reinfection with a different isolate of CMV (Ahlfors et al., 1999; Boppana et al., 2001; Novak et al., 2008). Documented evidence indicates that in the United States of America (USA), 38,000 children are born with congenital infection every year; $13 \%$ of these children develop symptomatic infection and $14 \%$ of those with asymptomatic infection develop symptomatic disease on follow-up during the first 5 years of life (Dollard et al., 2007; Wang et al., 2011a).

Congenital infection in newborns leads to significant neurologic disorders such as mental retardation, cerebral palsy, seizure disorders and developmental delay and also causes permanent disabilities, such as hearing and vision loss and cognitive impairment (Revello et al., 2006).

\section{Clinical translations to prevent HCMV}

Alongside of all the consequences of HCMV infection, there has been a considerable effort made towards the development of a HCMV vaccine, with particular emphasis on protection of pregnant women and immune-compromised persons (Schleiss, 2008; Dasari et al., 2013). It is over a decade since the United States (US) Institute of Medicine of the National Academy of Sciences assigned the highest priority for a vaccine to prevent congenital human CMV infection, which was subsequently endorsed by the National Vaccine Program in both US and EU countries. In spite of extensive efforts over many years, successful licensure of a HCMV vaccine formulation remains elusive (Dasari et al., 2013).

Persistent viruses represent a serious and worldwide clinical problem, thus the knowledge of the targets and mechanisms by which HCMV immunomodulation is achieved is an important step in search for new therapeutic strategies and potential pharmacological targets. Initially, it was assumed that blocking HCMV infection through neutralizing antibodies was sufficient for vaccine formation, but studies conducted in various disease environments, particularly transplant patients, clearly highlighted the importance of cellular immunity. A number of new vaccine candidates have been found to 
be effective in preclinical studies, and are able to induce CMV-specific immune responses in clinical studies, although firm evidence for long-term efficacy is not yet available (Revello et al., 2006).

\section{Consequences of the selective pressure}

As we know, the immune system protects host organism against the foreign pathogens while using the antigen presentation mechanism on the cells to eliminate the foreign pathogens through an antibody response or by activation of effector cells. As many viruses, HCMV is under constant selective pressure from the immune system. In vivo, there is pressure to retain immunomodulatory functions as a result of selection from the host immune system, while this is not the case in vitro. Only $26 \%$ ( 45 of 171) of the canonical HCMV genes are necessary for replication in vitro (Dunn et al., 2003; Yu et al., 2003), and selection of mutants lacking genes that are either not required, or are inhibitory, in vitro, occurs within a few weeks of isolation, becoming more extensive as passage continues (Dolan et al., 2004; Bradley et al., 2009; Dargan et al., 2010; Stanton et al., 2010).

Among the viral gene products that are likely to be involved in immunomodulation are homologues of cellular receptors, major histocompatibility complex (MHC) class molecules, tumor necrosis factor (TNF) family of ligands and receptors, cytokines and chemokines. The summary of HCMV-encoded functions discussed in this review is shown in (Fig. 1). The viral genes encoding these homologues have been hijacked by the viruses during a long pathogen/host co-evolution. In this review, we will look at the mechanism by which HCMV shapes our immunity and modulates the immune response of the host and discuss the functions of these homologues in the pathogenesis of HCMV infections. Moreover, we will discuss the development of immunomodulatory biologics inspired by viral tricks alongside with the vaccine search against the HCMV.

\section{HCMV counterstrategies targeting the immune system}

Despite inducing a robust and diverse innate and adaptive immune response, HCMV successfully progresses through its three-phase infection and establishes lifelong détente with its host (Picarda and Benedict, 2018). To aid in this, HCMV has developed many sophisticated mechanisms targeting host immunity. It is likely that only one third of more than 750 HCMV ORFs are required for the entry and lytic replication (Yu et al., 2003), suggesting the rest has evolved to combat the host immune response. Our laboratory has studied several of these immune modulatory genes over the last years, primarily focusing on those that target and/or intersect with Ig- and TNF-family immune signaling pathways. These and many other HCMV immune evasion mechanisms have been reviewed in recent years (Marshall and Geballe, 2009; Loewendorf and Benedict, 2010; Lisnić et al., 2015; Patel et al., 2018; Picarda and Benedict, 2018), so we will focus on those here that we deem to be the most likely to impact the development of new age biotherapeutics.

\section{$U L / b^{\prime}$ locus - the genetic content lost from HCMV} cell culture in vitro

The double stranded DNA (dsDNA) genome of wildtype HCMV strains has a size of around $235 \mathrm{kbp}$, which is longer than all other human herpesviruses and one of the longest genomes of all human viruses in general. It has the characteristic herpesvirus class E genome architecture, consisting of two unique regions (unique long UL and unique short US), both flanked by a pair of inverted repeats (terminal/internal repeat long TRL/IRL and internal/terminal repeat short IRS/TRS). The genomes of commonly used variants of HCMV strains, Towne and AD169, each contain a substantial mutation in which an $\mathrm{UL} / \mathrm{b}^{\prime}$ locus at the right end of the UL region has been replaced by an inverted duplication of a region from the left end of the genome (Fig. 2) (Bradley et al., 2009). In both commonly used HCMV strains the $13-15 \mathrm{~kb}$ UL/b' region, UL133-UL150, has been lost by extensive passage (Cha et al., 1996; Bradley et al., 2009; Patel et al., 2018).

The $\mathrm{UL} / \mathrm{b}$ ' region encodes up to 22 canonical genes of which at least 5 genes (UL135, UL141, UL142, UL148, UL148A) have been identified to inhibit function of NK cells that are critical components of the innate immune system as they rapidly detect and destroy infected cells (Diefenbach, 2014).

Targeting pentameric complex (gH/gL/UL128) UL130/UL131A) for vaccine development

Over the past 15 years we have witnessed a surge in the development of multiple HCMV vaccines which have been tested but only partial protection has been achieved in these studies. In the development of various immunomodulatory approaches, to fight a broad range of human diseases, including cancer, viral infections, autoimmunity and inflammation as well as in the prevention of transplantant rejection, were mostly used monoclonal antibodies $(\mathrm{mAb})$ or recombinant fusion proteins that target cell surface signaling molecules on immune cells to drive immune responses towards the desired direction (Yao et al., 2013). 


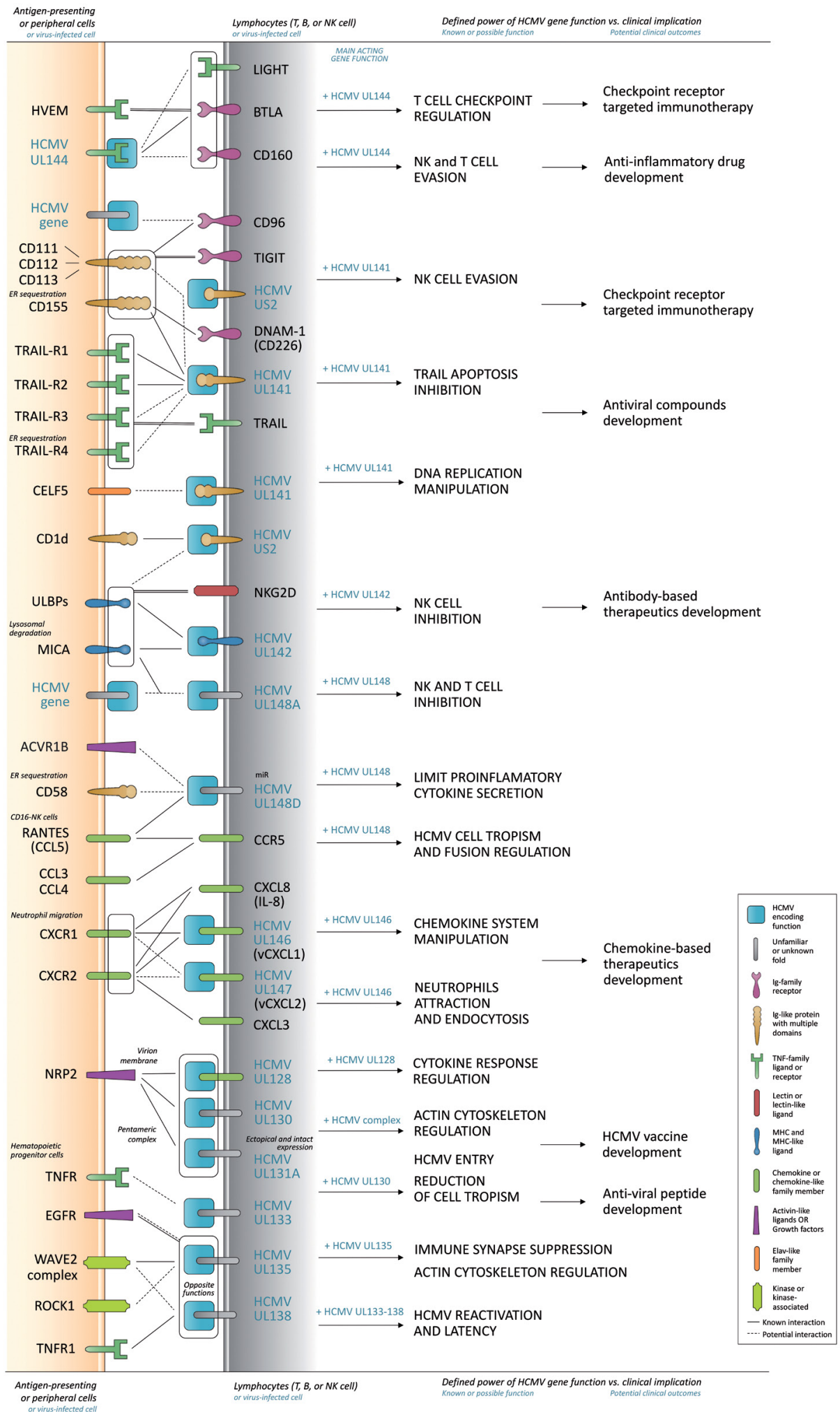

Fig. 1

Summary of HCMV-encoded functions originated from $\mathrm{UL} / \mathrm{b}$ ' genomic region discussed in this review (highlighted in cyan squares) The power of individual gene functions, both viral and endogenous, are present in the context of their known or possible function in immunomodulation as well as their clinical relevance. In particular, the family of acting ligand or receptor and/or protein fold is present in the legend. 
(a)

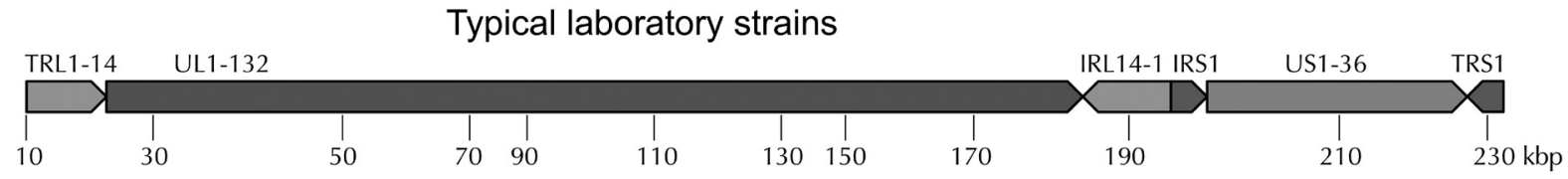

(b)

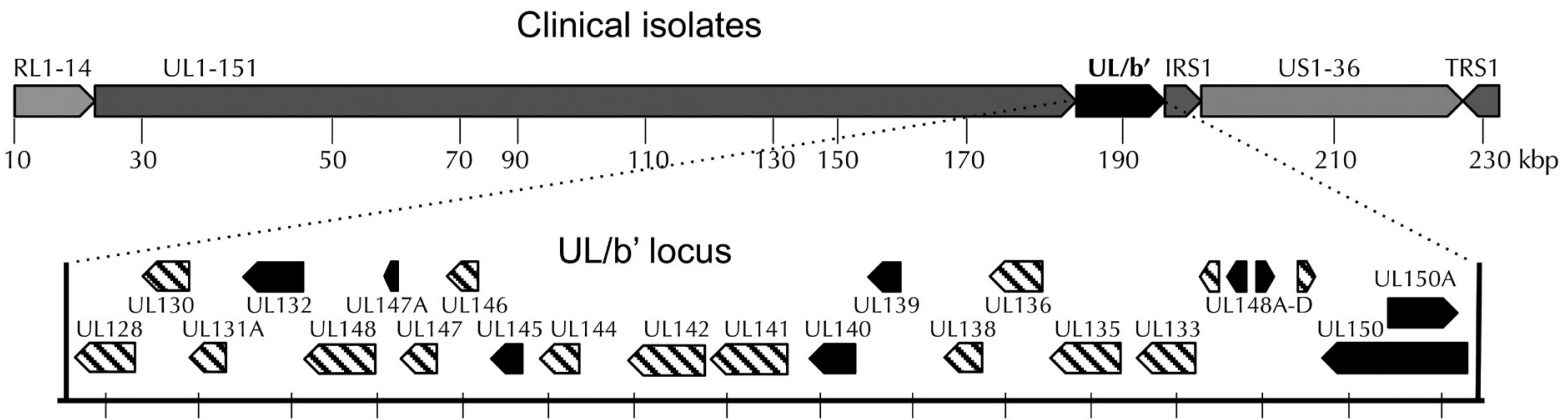

Fig. 2

The comparison of typical laboratory (a) versus clinical HCMV strain (b) highlights immunomodulatory function of UL/b' gene content (c) that seems to be critical in humans to regulate immunity

The genetic organization of two ORF maps of HCMV strains are shown with highlighted UL/b' locus (black) that is deleted in extensively passaged laboratory strains. Zoomed into UL/b' locus are annotated functional ORFs as reported in Murrell et al. (2016). Protein coding regions are indicated by arrows with ORF nomenclature above. The nucleotide positions are given in kbp (kilobase pairs). Genes whose functions are known and reviewed here are marked with stripes.

HCMV infection is dependent on the functions of structural glycoproteins at multiple stages of the viral life cycle. These proteins mediate the initial attachment and fusion events that occur between the viral envelope and a host cell membrane, as well as virion-independent cell-cell spread of the infection. For the entry of this virus are critical multiple surface-expressed glycoproteins, including glycoprotein $\mathrm{B}(\mathrm{gB})$, the $\mathrm{gM} / \mathrm{gN}$ complex, the gH/gL complex, and a pentameric gH/gL/UL128/UL130/ UL131A complex, which are the primary targets of neutralizing antibodies to HCMV (Britt et al., 1990; Rasmussen et al., 1991; Urban et al., 1996; Mach et al., 2000; Macagno et al., 2009; Fouts et al., 2012), while UL128, UL130 and UL131A are genetic content of UL/b' locus of HCMV. The gB and gH elicit a large fraction of the antibodies that neutralize infection of cultured fibroblasts (Britt et al., 1990; Rasmussen et al., 1991; Urban et al., 1994; Macagno et al., 2009; Pötzsch et al., 2011; Wang et al., 2011b; Fouts et al., 2012). The gH associates with gL (Kaye et al., 1992), and gH/gL and gB form the conserved herpesvirus fusion machinery (Heldwein and Krummenacher, 2008) that is required for HCMV infection in fibroblasts. The gH/gL can also associate with UL128, UL130, and UL131A to form a pentameric complex (Wang and Shenk, 2005b; Adler et al., 2006; Ryckman et al., 2008). Proteins encoded by UL128, UL130, and UL131A complex with gH and gL on the virion surface to mediate entry into endothelial cells, leukocytes, and dendritic cells by endocytosis (Hahn et al.,2004; Wang and Shenk, 2005a,b; Adler et al.,2006; Ryckman et al.,2006, 2008; Scrivano et al., 2011). This complex is not required for entry into fibroblasts; rather, HCMV enters fibroblasts by fusion mediated by the gH/gL/gO complex (Compton et al., 1992; Li et al., 1997; Huber and Compton, 1998). HCMV strains passaged in fibroblasts accumulate mutations in the UL128-UL131A locus, resulting in lost tropism for endothelial and epithelial cells (Hahn et al., 2004; Wang and Shenk, 2005a,b; Ryckman et al., 2006; Dargan et al., 2010) and reduced transfer of virus to leukocytes (Hahn et al., 2004). However, laboratory strains competent for entry into endothelial cells (e.g., encoding wild-type or repaired UL131A) still replicate to reduced yields relative to several clinical strains (Hahn et al., 2004; Wang and Shenk, 2005a).

An abundance of data has demonstrated that this pentameric complex is required for HCMV entry into dendritic, epithelial and endothelial cells (Akter et al., 2003; Hahn et al., 2004; Gerna et al., 2005). Loomis et al., 2013 showed that viral replicon particles (VRPs) expressing the $\mathrm{gH} / \mathrm{gL}$ complex elicited more potent neutralizing antibodies than VRPs expressing gB in mice. Also, Wen et al.(2014) investigated the immunogenicity of VRPs encoding the HCMV gH/gL and pentameric complexes. The results of these studies indicate that the pentameric complex elicits significantly higher levels of neutralizing antibodies than the $\mathrm{gH} / \mathrm{gL}$ complex. In addition, when the animals were immunized with pentamer encoding VRPs or subunit of pentamer the animals produced antibodies that were 
able to recognize a broad spectrum of antigenic sites on the complex (Wen et al., 2014). These results indicate that the pentameric complex consisting of three $\mathrm{UL} / \mathrm{b}$ ' genes and two glycoproteins can be useful in the development of HCMV vaccine candidates.

\section{Development of antiviral peptides inspired by UL130}

In the development of antiviral peptides appears to be a promising candidate the UL130 gene product of HCMV UL/b' locus, due to its $C$ terminus, which plays an important role in HCMV-infected endothelial cells. In order to define functionally important peptides within this protein, the charge-cluster-to-alanine (CCTA) mutational scanning of UL130 in the genetic background of a bacterial artificial chromosome-cloned endotheliotropic HCMV strain was done. A total of 10 charge clusters were defined, and in each of them two or three charged amino acids were replaced with alanine. While the six N-terminal clusters were phenotypically irrelevant, mutation of the four C-terminal clusters each caused a reduction of cell tropism (Schuessler et al., 2010).

Malkowska et al. (2013) hypothesized that CMV UL130 gene might encode an orthologous chemokine like protein, which was investigated by the crystallographic determination of the structure of two gH/gL complexes. Chowdary et al. (2010) solved the crystal structure of the herpes simplex virus 2 (HSV-2) gH/gL complex, whilst Matsuura et al., 2010 described the crystal structure of an Epstein-Barr virus (EBV) complex (Chowdary et al., 2010; Matsuura et al., 2010). The topologies of both glycoproteins are highly concordant with the homology models (Wyrwicz and Rychlewski, 2007). In the study of structural similarity of glycoprotein gL in CMV UL130 with chemokines it was found that rat CMV r131 gene encoding a proinflamatory CC chemokine-like proteins has been recognized as HCMV UL130 homolog (Kaptein et al., 2004; Vomaske et al., 2012). The position of conserved cysteines $\left(1^{\text {st }}\right.$ and $3^{\text {rd }}$ cysteine of characteristic CXC type chemokine motif) leads to the assignment of UL130 to C type chemokine subfamily (Malkowska et al., 2013). Despite of the loss of $2^{\text {nd }}$ and $4^{\text {th }}$ cytosine the chemotactic activity might be preserved and requires further investigation as it might explain the mechanism of UL130 functioning in endothelial cell infection (Patrone et al., 2005). The hypothesis concerning the co-evolution of the two interacting glycoproteins (Matsuura et al., 2010) causes us to presume that the most likely cause of such concordance is that gL arose as a result of lateral gene transfer from the host. It is very likely that early in the evolution of Herpesviridae, gL acted predominantly as a virus encoded chemokine [compare viral chemokines:
UL146, UL147, UL152 encoded by HCMV (Vink et al., 1999)], which later co-evolved with the other membrane viral genes (Malkowska et al., 2013).

\section{UL133-UL138 locus as a post entry tropism deter- minant required for viral maturation}

The molecular mechanisms governing HCMV persistence in the infected host are largely unknown, in part, because the viral determinants and cellular reservoirs of persistence are weakly defined. The endothelial cells are an important interface for bidirectional virus spread (Britt, 2008; Adler and Sinzger, 2009). Endothelial cells are considered a key target of CMV infection in humans (Sinzger et al., 1995) but they have different susceptibilities and support distinct modes of infection in vitro depending on their anatomical source and type (Sinzger et al., 1997, 2000; Fish et al., 1998; Kahl et al., 2000; Jarvis and Nelson, 2007). By this cell type- or cell origin-dependent gradation in viral replication endothelial cell-specific determinants control infection outcomes ranging from lytic replication to latency (Jarvis and Nelson, 2002, 2007).

In the UL/b' region, the UL133-UL138 locus which is important for the latent infection in $\mathrm{CD}_{3} 4^{+}$hematopoietic progenitor cells (HPCs) was identified. This locus, which encodes four proteins, pUL133, pUL135, pUL136, and pUL138, is not suitable for replication in fibroblasts but for efficient replication in endothelial cells, infected with the TB40E or fusion-inducing factor X (FIX) HCMV strain, is needed. It was found, if the endothelial cells are not infected with the entire locus (UL133-UL138) of HCMV, virus complete the immediate-early and early phases of infection but are defective for infectious progeny virus production, the differences in the organization of intracellular membranes and in the assembly of mature virions in the comparison of endothelial cells infected with wildtype virus are present, Golgi stacks are disrupted, and the viral assembly compartment characteristic of HCMV infection failed to form (Bughio et al., 2013).

UL/b' genes (UL135, UL128, UL130, UL131A) act in regulation of actin cytoskeleton

HCMV infection of monocytes leads to a wide range of biological changes that shape the behavior of target monocytes. HCMV-infected monocytes are characterized by the overexpression and secretion of inflammatory cytokines, an enhanced cellular motility, the increased expression of adhesion molecules allowing for tight adhesion of infected monocytes to endothelial cells, an increase in transendothelial migration, and the promotion of cellular differentiation (Yurochko and Huang, 1999; Smith et al., 
2004,2007). HCMV by engaging cellular receptors changes the biology of blood monocytes, allowing for efficient viral entry into these cells and their use as virus-carriers in HCMV systemic spread. These biological changes of target monocytes shape their behavior. HCMV-infected monocytes are characterized by the overexpression and secretion of inflammatory cytokines, an enhanced cellular motility, the increased expression of adhesion molecules allowing for tight adhesion of infected monocytes to endothelial cells, an increase in transendothelial migration, and the promotion of cellular differentiation. However, it remains unclear, assuming the fact that HCMV specifically induces this observed activation of monocytes. The biological changes seen in HCMV-infected monocytes allow the virus to use the natural sentinel role of circulating monocytes to exit the blood stream and translocate to multiple host organ tissues, where monocytes, which are nonpermissive for viral replication, undergo a distinct HCMV-driven differentiation into macrophages that support viral replication and production of progeny virions. Only virions possessing the pentameric complex are capable of activating integrin/Src/paxillin-signaling in monocytes. Nevertheless, the mechanism by which the gH/gL/UL128/UL130/UL131A complex promotes this process is also unknown. The HCMV pentameric complex has an inhibitory effect on integrin mediated signaling in fibroblasts. For the virus entry process into the monocytes is critical appropriate actin and dynamin regulation. From data, the HCMV gH/gL/UL128/UL130/UL131A complex emerges as the specific ligand driving the activation of the receptor-mediated signaling required for the regulation of the actin cytoskeleton (Nogalski et al., 2013).

UL135, by remodelization of the actin cytoskeleton, suppresses formation of the immunological synapse ( $\mathrm{Pa}-$ tel et al., 2018). When the cells were infected with Merlin UL135 strain, cells were less rounded when assessed by microscopy, and cells did not exhibit loss of F-actin from the center of the cell that is normally observed following HCMV infection, implying that UL135 had an important role in the characteristic cytopathic effect induced by HCMV. In addition, pUL135 interacted directly with Abelson interactor 1(ABI1) and ABI2 to recruit the WAVE2 regulatory complex to the plasma membrane, remodel the actin cytoskeleton and dramatically reduce the efficiency of immunological synapse formation. Furthermore, the correlation exists between the presence of actin fibers in the target cell and the structure of the immune synapse formed with NK cells. F-actin in target cells plays a critical role, when F-actin fibers were disrupted by UL135 expression; the ability of the NK cells to form an immune synapse was impaired. The formation of effective immunological synapse is requirement in the effector cell and this requirement is targeted by HCMV to mediate immune-evasion (Takenawa and Suetsugu, 2007; Stanton et al., 2014).

\section{UL141 keeps HCMV in charge}

The UL141 is the first HCMV gene with primary NK cells evasion role that acts to suppress two and more NK-signaling mechanisms. Infection with HCMV clinical isolates consistently bestowed substantially more effective protection from NK cell attack than did the highly passaged laboratory strain AD169, proving that NK cellevasion functions have consistently been lost in vitro. Use of a recombinant HCMV consisting of Towne and the $\mathrm{UL} / \mathrm{b}$ ' region from Toledo revealed that transferring the UL/b' region conferred resistance to NK cell killing. For this phenotype, a UL141 gene was responsible. The UL141 was capable of suppressing killing of $67 \%$ of all NK cell clones tested, consistent with targeting of a principal NK cell-regulatory pathway by the gene. The UL141 has a broad inhibitory effect on the NK cells by its cellular target, CD155 (poliovirus receptor/nectin like molecule 5). CD155 is a ligand for the activating receptor CD226 (DNAM-1; DNAX accessory molecule 1). UL141 inhibits expression not only of CD155 but also expression of another NK cells activating ligand, CD112, and cellular death receptors (TRAIL-R1-4; TNF-related apoptosis-inducing ligand receptors 1-4) for the apoptosis-inducing ligand TRAIL (Tomasec et al., 2005; Smith et al., 2013).

The fact that UL141 inhibits NK cell ligand expression for the CD155, DNAM-1 activating receptor, was found by extensive screening of known ligands activating NK cells on the surface of cells infected with rAdUL141 (replication deficient adenoviruses). When UL141 was bound and sequestrated inside the endoplasmic reticulum (ER), the surface expression of CD155, a protein normally involved in formation of stromal cell-cell junctions (Maier et al., 2007) and an activating ligand for DNAM-1 (CD226) and CD96 on NK cells (Bottino et al., 2003; Fuchs et al., 2004), was impaired. Functions of UL141 were observed by subcloning a HCMV $\triangle$ UL141 strain from TB40E (Tomasec et al., 2005). In addition, Bottino et al., 2003 found that another ligand for DNAM-1, is also downregulated upon HCMV infection and rescued by deletion of UL141 from Merlin strain but using a different mechanism (Bottino et al., 2003; Prod'homme et al., 2010). For downregulation and degradation of CD112 ligand, UL141 also utilizes another gene that is located outside the UL/b' region, US2. UL141, in conjunction with US2, uses the same mechanism by which US2 induces HLA-I (human leukocyte antigen I) heavy chain proteasomal degradation, namely the TRC8dependent mechanism (Hsu et al., 2015). HCMV UL141 can directly bind HCMV US2 and form a multimeric complex with CD112 (Nemčovičová et al., unpublished data). 
UL141 also restricts expression of the death receptors for TNF-related apoptosis inducing ligand receptors 1 and 2 (TRAIL-R1 and R2), binding directly to both TRAIL-R1 and-R2 ectodomains (Nemčovičová et al.,2013). Death receptors are cell surface receptors that transmit apoptotic signals initiated by specific ligands, e.g. TRAIL. These receptors play a central role in instructive apoptosis and belong to the tumor necrosis factor receptor (TNFR) gene superfamily. They consist of cysteine rich extracellular subdomains and a homologous cytoplasmic sequence termed the "death domain". Adaptor molecules interact with the death receptors and transmit the apoptotic signal to the death-machinery (Mahalingam et al., 2009; Nemčovičová and Zajonc, 2014). UL141 is responsible for downregulation of both TRAIL-R1 and -R2 during HCMV infection, also through the ER (Nemčovičová et al., 2013; Smith et al., 2013). In addition, it has been found that overexpression of UL141 through replication-deficient adenoviruses (rAds) is protected during apoptosis, while cells infected with HCMVDUL141 on a strain FIX background were more susceptible, to TRAIL-dependent NK cell killing (Smith et al., 2013).

Structural study of the Ig-like domain of UL141 and the CD155 ligand TIGIT (T-cell immunoreceptor with Ig and ITIM domains) revealed that UL141 could potentially engage CD155 similar to TIGIT by using the C'C" and GF loops. Further mutations in the TIGIT binding site of CD155 (Q63R and F128R) abrogated UL141 binding, suggesting that the Ig-like domain of UL141 is a viral mimic of TIGIT, as it targets the same binding site on CD155 using similar 'lock-and-key' interactions. Sequence alignment of the UL141 gene and its orthologues also showed conservation in this highly hydrophobic (L/A) $\mathrm{X}_{6} \mathrm{G}$ 'lock' motif for CD155 binding as well as conservation of the TRAIL-R2 binding patches, suggesting that these host-receptor interactions are evolutionary conserved (Nemčovičová and Zajonc, 2014).

In a recent study by Murrell et al. (2016) it has been found that all known mutations in the (UL)/b' region in epithelial cells involved the loss or mutation of the UL141 gene (Murrell et al., 2016). Such modulation of the immune response permits persistence of the virus in the host organism. UL141 is remarkable in that it prevents NK cell mediated cytotoxicity by targeting at least 4 different proteins using two independent mechanisms of intracellular retention and proteasomal degradation (Picarda and Benedict, 2018). Therefore, it is necessary to elucidate the interactions between UL141 and other human proteins and also to find out which ectodomains use UL141 to reverse the immune response of the organism.
UL142 interferes on MHC-class proteins in virusprotective manner

Some of the HCMV-encoded gene products modulate NK cell activity as ligands expressed at the cell surface that engage inhibitory NK cell receptors, whereas others prevent the infected cell from upregulating ligands that bind to activating NK cell receptors (Bennett et al., 2010). The viral protein UL142 interferes with NK group 2D (NKG2D)-mediated NK cell activation. NKG2D, homodimeric receptor, is a major activating NK receptor (NKR) expressed on all human NK cells ex vivo (Bauer et al., 1999). Human cells express at least eight NKG2D ligands (NKG2DLs): MIC A/B, ULBP1-3, RAET1E(ULBP4), RAET1G (ULBP5), and RAET1L (ULBP6). It was shown that viral UL16 of HCMV is able to prevent the surface expression of four of these ligands (MIC B and ULBP1, 2, and 6) but not the related ULBP3 and MIC A (Cosman et al., 2001; Eagle et al., 2009). Downregulation of surface expression of the closely related MIC A was also demonstrated in HCMVinfected cells mediated by UL142 protein (Chalupny et al., 2006). Bennett et al. (2010) showed that the HCMV gene product UL142 can prevent cell surface expression of ULBP3 during infection. UL142 prevents ULBP3 trafficking to the surface and protects transfected cells from NK-mediated cytotoxicity. In addition, it was shown that HCMV-infected cells can downregulate surface levels of ULBP3, while only wild-type virus has this property, and that the laboratory-adapted strain AD169, missing the $\mathrm{UL} / \mathrm{b}$ ' region, is unable to control ULBP3 surface expression. UL142 is unable to downmodulate mature ULBP3 from the cell surface; instead, it promotes retention of nascent ULBP3 protein in the cis-Golgi, thereby preventing trafficking of the NKG2DL to the cell surface.

HCMV tropism modulator UL148 activates the unfolded protein response

UL148 is a viral ER-resident glycoprotein encoded by HCMV that acts as an inducer of the unfolded protein response (UPR) and contributes to HCMV cell tropism. UL148 has a potential to promote the expression of gO, a viral envelope glycoprotein that participates in a heterotrimeric complex with gH and gL that is required for infectivity.gO is constitutively degraded during infection by the ER-associated degradation (ERAD) pathway and UL148 interacts with the ERAD machinery and slows gO decay (Nguyen et al., 2018; Siddiquey et al., 2018).

On the surface of $\mathrm{T}$ and NK cells an important costimulatory molecule, CD2 is located. CD2 is able to bind to CD58 (LFA-3) on the surface of antigen presenting cells (APC) (Thomas, 1989). The role of the CD58:CD2 signaling is important for adaptive NK cell activity as 
well as regulating cell adhesion and the immunological synapse formation (Leitner et al., 2015). On the surface of HCMV infected cells, following AD169 infection, CD58 was upregulated (Grundy and Downes, 1993) and later it was identified that the difference in CD58 expression correlated with the amount of NK mediated killing (Fletcher et al., 1998). Rölle et al., 2016 showed that blocking CD58 on the surface of AD169-infected MRC-5 fibroblasts resulted in reduced interferon gamma (IFN $\gamma)$ and TNF production by NK cells (Rölle et al., 2016). Later research with Merlin-infected cells also led to a decrease in CD58 on the surface of fibroblasts (Weekes et al., 2014; Fielding et al., 2017), as a result of UL148-mediated sequestration in the ER (Wang et al., 2018). The greatest effect of UL148 on NK cell activation was recorded in context of antibody dependent cellular cytotoxicity (ADCC) and there exists a correlation with contribution of the CD2:CD58 pathway (McSharry et al., 2012).

Prototype anti-inflammatory drug inspired by viral tricks of UL144

UL144 has been reported to have several functional consequences on antiviral immunity, one being induction of production of CCL22 (a macrophage-derived chemokine) via TRAF-6 (TNF receptor-associated factor 6)-mediated NF- $\kappa B$ (nuclear factor- $\kappa B$ ) signaling to enhance Th2 responses. UL144 causes constitutive NF- $\kappa B$ activation by recruitment of TRAF- 6 , while CCL22 is a chemotactic factor, which may affect migration of CCR4 expressing NK cells (Poole et al., 2006, 2008; Yoshie and Matsushima, 2015). In contrast, UL144 can also be anti-inflammatory by evading CD160-mediated activation of NK cells. Together, these data indicate that UL144 likely plays multiple roles in regulating immunity to $\mathrm{CMV}$ infection.

In addition, UL144 is known as an immunoevasin that encodes an ortholog for the herpes virus entry mediator (HVEM) a member of TNF receptor superfamily (TNFRSF14). HVEM is a focal point for manipulation by viral pathogens including CMV (Benedict et al., 1999). It interacts with multiple ligands expressed in the immune system including the TNF superfamily cytokines, LIGHT and lymphotoxin- $\alpha$ (LT- $\alpha$ ), the immunoglobulin superfamily members BTLA (B- and T-lymphocyte attenuator) and the natural killer cell-activating receptor CD160 that serve as checkpoint regulators in T cells (Ware and Šedý, 2011). As receptors for HVEM are found on T and NK cells, it was predicted that UL144 would affect both these effector subsets. In the presence of plate bound UL144, the significant reduction of CD4+ T-cells proliferation was reported (Cheung et al., 2005). This was attributed to the binding of UL144 to BTLA, a co-inhibitory receptor. However, UL144 selectively binds BTLA, avoiding activa- tion of inflammatory signaling initiated by CD160 in NK cells. Unlike HVEM, UL144 is not capable to bind CD160, which normally provides a co-stimulatory signal for NKcells promoting cytolytic activity. For this reason, UL144 has been proposed to provide a specific inhibitory signal via BTLA counterbalancing HVEM-induced activation signals through CD160 (Šedý et al., 2013, 2017). Further investigation has revealed that posttranslational modifications (PTM) on UL144 are also involved in receptor recognition machinery of HCMV (Nemčovičová et al., unpublished data). Wild-type UL144 maintains more than 10 potential glycosylation sites located in extracellular part of the gene, while its ortholog, HVEM, has only one site in CRD2. Many of them are not present in viruses of other species suggesting that potential glycosylation on UL144 is important only in humans and may play a role in ligandbinding recognition. Our recent study has indicated that glycosylation-deficient (GD) mutant of recombinant UL144 could bind CD160 with similar affinity as observed for soluble HVEM, while this GD mutant is still unable to bind LIGHT. These data together highlight importance of UL144 glycosylation in HCMV immune recognition.

In addition, BTLA and CD160 cross-compete for binding HVEM. The UL144 structure closely mimics the surface of HVEM (Bitra et al., 2019), and there was also found that both HVEM and UL144 bind a common epitope of BTLA, whether engaged in trans or in cis, that is shared with a BTLA antibody agonist (Šedý et al., 2017). Furthermore, these recent results illuminate structural differences between UL144 and HVEM that explain its binding selectivity and highlight it as a suitable scaffold for designing superior, immune inhibitory BTLA agonists.

Other genes in $U L / b^{\prime}$ region with potential to modulate NK cell function

In the regulation of MIC A expression, the UL148A appears to be a very promising candidate for its ability to downregulate MIC A expression. The UL148A targets specific MIC A allotypes that are ligands for NKG2D. By using HCMV knock-out viruses on an AD169VarL background UL148A was identified (Dassa et al., 2018; Patel et al., 2018). UL148A is not sufficient for MIC A targeting, but rather acts in concert with an unknown viral factor. Using inhibitors of different cellular degradation pathways, UL148A targets MIC A for lysosomal degradation and in addition, UL148A-mediated MIC A downregulation hampers NK cell-mediated killing of HCMV-infected cells (Dassa et al., 2018).

Another gene in $\mathrm{UL} / \mathrm{b}^{\prime}$ region with potential to modulate NK cells is UL148D. In the study of this gene, it was found that a HCMV-encoded miRNA, miR-UL148D, robustly accumulates during late stages of experimental 
latent HCMV infection in host cells and promotes HCMV latency by modulating the immediate early response gene 5 (IER5)-cell division cycle 25B (CDC25B) axis in host cells. The miR-UL148D efficiently inhibited the up-regulation of IER5 during latent viral infection, maintaining the activity of CDC25B and cyclin-dependent kinase 1(CDK1) and thus controlling immediate early 1 (IE1) transcription (Pan et al., 2016). The miR-UL148D has been shown also in a lytic infection to target chemokine RANTES (regulated on activation, normal T-cell expressed and secreted). The ligand for RANTES, CCR5, can be detected on CD16- NK cells, which migrate upon RANTES treatment (Campbellet al.,2001). Therefore, the prevention of RANTES production may potentially affect the migration of NK cells toward HCMV infected cells.

UL146 and UL147 ablate antiviral immunity by manipulating the host chemokine system

As mentioned earlier, HCMV possesses genes that encode factors involved in immune evasion, which could function to increase viral spread and survival. It encodes CXC chemokine homolog UL146 (vCXCL-1), UL147 (vCXCL-2), UL128 (Akter et al., 2003), and chemokine receptors (McSharry et al., 2012). Both the UL146 and UL147 genes are located at the UL/b' boundary and in 19 ORFs between UL133 and UL151; these genes are also getting lost after extensive serial passaging of the Towne and AD169 strains in tissue culture. These two genes exhibit high intra strain variability, although no functional differences have yet been reported to be associated with these variants (Sijmons et al., 2015). Moreover, the UL146 gene is one of the most variable genes in the HCMV genome, and 14 genotypes have been catalogued (Arav-Boger et al., 2005). It has been suggested that HCMV could abate antiviral immunity by manipulating the host chemokine system and suppressing the immune system.

In the study of Lüttichau (2010), the UL146 was probed against a panel of the 18 classified human chemokine receptors. In calcium mobilization assays UL146 acted as an agonist on both CXCR1 and CXCR2 but did not activate or block any of the other 16 chemokine receptors. UL146 was characterized and compared with other receptors. The affinities of UL146 for the CXCR1 and CXCR2 receptors were 44 and $5.6 \mathrm{nM}$, respectively, as determined in competition binding against radioactively labelled CXCL8. In various assays UL146 acted as a highly efficacious activator of both receptors, with a rather low potency for the CXCR1 receptor but comparable with CXCL5 and CXCL7. It is suggested that CMV uses the UL146 gene product expressed in infected endothelial cells to attract neutrophils by activating their CXCR1 and CXCR2 receptors, whereby neutrophils can act as carriers of the virus to uninfected endothelial cells. In that way a lasting pool of CMV-infected endothelial cells could be maintained.

\section{Conclusions}

Persistent viruses represent a serious and worldwide clinical problem, thus the knowledge of the targets and mechanisms by which CMV immunomodulation is achieved is an important step in our search for new therapeutic strategies and potential targets. When developing new therapeutic biological agents, it is important to think about minimizing the adverse effects of these substances as well as their long-term use. Immunomodulatory biological agents have the potential to treat diseases that are associated with immune system disorders such as hyperactive conditions, inflammatory diseases, autoimmune diseases as well as transplant rejection, or immune responses stimulated to reverse hypoactive immune responses in cancer or chronic bacterial or viral infections.

In the development of various immunomodulatory approaches, to fight a broad range of human diseases, were mostly used mAb-based therapeutics, which neutralize or target positive cells (Chan and Carter, 2010; Weiner et al., 2010), or recombinant fusion proteins that can engage and manipulate cell surface signaling molecules on host immune cells to modulate antigen-specific receptor signals to control the direction and magnitude of lymphocyte responses (Yao et al., 2013). Since immunomodulatory biological agents act on the basis of two mechanisms of action: antagonists (blocking or neutralizing the interaction between receptors and ligands) or agonists (inducing receptor signaling by mimicking ligand) and, in addition, lymphocyte activation can be inhibited to suppress unwanted immunity either by blocking co-stimulatory receptors or triggering a negative regulatory pathway, it is extremely important, due to the temporal and spatial differential expression of co-signaling molecules during immune activation and their differential involvement in cancer and viral evasion, to understand the mechanism of individual pathways to design the most effective therapeutic biological agents with minimized side effects on the immune system.

Research of HCMV genomic stability and its effect on NK cells function has provided important insights into host-virus interactions, but future studies will require consideration of genetic variability and the effect of genes expressed in the context of infection to fully understand their in vivo impact.

HCMV encodes $>170$ viral proteins, more than half of which are able to modulate the host's immune response. The UL/b' genomic region contains genes that are responsible for human immunomodulation. Many genes 
in this region are directed to the inhibition of NK cells, which are an important part of the immune system. At least 5 genes from this locus, UL135, UL141, UL142, UL148, UL148A inhibit NK cell function. In addition, UL135 is also involved in the remodeling of actin cytoskeleton thereby inhibiting the production of immunological synapses as well as the UL128, UL130 and UL131A act in the regulation of the actin cytoskeleton. The UL130 is also part of the pentameric complex gH/gL/UL128/UL130/UL131A, which is one of the primary targets of neutralizing antibodies to HCMV and thus an important agent for vaccine development. In the UL/b' region there is an UL133-UL138 genomic region which is an important post-entry tropism determinant required for viral maturation. As such cell tropism modulator is also known UL148, which activates unfolded protein response. UL146 and UL147 in turn ablate antiviral immunity by manipulating the host chemokine system and suppress the immune system.

An extraordinarily effective strategy is encoded by the HCMV UL141 protein, which inhibits cell surface expression of the CD155 and CD112 to activate NK via DNAM-1 and CD96. Moreover, it was found that UL141 binds CD155 ectodomain by lock-and-the-key mechanism, thus mimicking another important cellular 'checkpoint' receptor TIGIT. In addition, UL141 also binds and inhibits expression of the death receptors for the TNF family apoptotic ligand TRAIL. This pleiotropy of UL141 is required for its broad and potent inhibition of NK cells, and a viral mutant lacking UL141 is highly susceptible to NK killing, revealing how disrupting the function of a single HCMV immune-modulating gene can tip the balance in favor of host defense.

In regards to regulation of immunity, HCMV UL144 gene product plays multiple roles. UL144 is an orthologue of HVEM that selectively binds the co-inhibitory 'checkpoint' molecule BTLA and potently blocks T cell proliferation. On the other hand, the UL144 glycosylation plays also role in HCMV immune recognition and thus making it useful in the preparation of anti-inflammatory drugs based on the viral tricks.

Nevertheless, our overall understanding of how HCMV evades and modulates intrinsic immune sensors and effectors during infection remains still superficial. Viruses are in a constant arms race with the host immune system, hijacking host proteins and modulating their function to ensure survival. It is not exactly known which viral proteins are actually present at the cell surface or which are retaining in the ER, or how viral and host proteins are cross interacting and how they are regulated during infection. Answering such questions has the potential to reveal novel mechanisms of immune evasion, new cell surface drug targets resulting in new immunomodulatory biologics and an improved understanding of HCMV biology. Therefore, the challenging next step will be to translate this increasing knowledge into prophylactic and therapeutic applications.

Acknowledgment. The work was supported by the contribution of the Slovak Research and Development Agency under the project APVV-14-0839 and APVV-15-0474 and the contribution of the Scientific Grant Agency of the Slovak Republic under the grant Nos. 02/0020/18 and 02/0130/18. IN is Marie Curie Fellow financed by Programme SASPRO co-funded by European Union and the Slovak Academy of Sciences under the contract 0003/01/02. The authors gratefully acknowledge the contribution of the project BIOFARMET under the contract No. ITMS26240220096. The part of the research team is supported by Interreg V-A SK-AT cooperation programme by project CAPSID under the contract No. NFP305010V235 co-financed by European Regional Development Fund.

\section{References}

Adler B, Scrivano L, Ruzcics Z, Rupp B, Sinzger C, Koszinowski U., J. Gen. Virol. 87, 2451-2460, 2006.

Adler B, Sinzger C., Thromb. Haemostasis 102, 1057-1063, 2009. https://doi.org/10.1160/TH09-04-0213

Ahlfors K, Ivarsson SA, Harris S., Scand. J. Infect. Dis. 31, 443-457, 1999. https://doi.org/10.1080/00365549950163969

Akter P, Cunningham C, McSharry BP, Dolan A, Addison C, Dargan DJ, Hassan-Walker AF, Emery VC, Griffiths PD, Wilkinson GW, Davison AJ., J. Gen. Virol. 84, 1117-1122, 2003. https://doi.org/10.1099/vir.0.18952-0

Arav-Boger R, Zong JC, Foster CB, Virus Genes 31, 65-72, 2005. https://doi.org/10.1007/s11262-005-2201-3

Bauer S, Groh V, Wu J, Steinle A, Phillips JH, Lanier LL, Spies T., Science 285, 727-729, 1999. https://doi.org/10.1126/ science.285.5428.727

Benedict CA, Butrovich KD, Lurain NS, Corbeil J, Rooney I, Schneider P, Tschopp J, Ware CF., J. Immunol. 162, 6967-6970, 1999.

Bennett NJ, Ashiru O, Morgan FJ, Pang Y, Okecha G, Eagle RA, Trowsdale J, Sissons JG, Wills MR., J. Immunol. 185, 1093-1102, 2010. https://doi.org/10.4049/jimmu$\underline{\text { nol.1000789 }}$

Bitra A, Nemčovičová I, Picarda G, Doukov T, Wang J, Benedict CA, Zajonc DM., J. Biol. Chem. 294, 10519-10529, 2019. https://doi.org/10.1074/jbc.RA119.009199

Boppana SB, Rivera LB, Fowler KB, Mach M, Britt WJ., New. Engl. J. Med. 344, 1366-1371, 2001. https://doi.org/10.1056/ NEJM200105033441804

Bottino C, Castriconi R, Pende D, Rivera P, Nanni M, Carnemolla B, Cantoni C, Grassi J, Marcenaro S, Reymond N, Vitale M, Moretta L, Lopez M, Moretta A., J. Exp. Med. 198, 557-567, 2003. https://doi.org/10.1084/jem.20030788

Bradley AJ, Lurain NS, Ghazal P, Trivedi U, Cunningham C, Baluchova K, Gatherer D, Wilkinson GW, Dargan DJ, Davison AJ., J. Gen. Virol. 90, 2375-2380, 2009. https:// doi.org/10.1099/vir.0.013250-0 
Britt W., Curr. Top. Microbiol. 325, 417-470, 2008. https://doi. org/10.1007/978-3-540-77349-8_23

Britt WJ, Vugler L, Butfiloski EJ, Stephens EB., J. Virol. 64, 1079-1085,1990. https://doi.org/10.1128/JVI.64.3.10791085.1990

Bughio F, Elliott DA, Goodrum F., J. Virol. 87, 3062-3075, 2013. https://doi.org/10.1128/JVI.02510-12

Campbell JJ, Qin S, Unutmaz D, Soler D, Murphy KE, Hodge MR, Wu L, Butcher EC., J. Immunol. 166, 6477-6482, 2001. https://doi.org/10.4049/jimmunol.166.11.6477

Cha TA, Tom E, Kemble GW, Duke GM, Mocarski ES, Spaete RR., J. Virol. 70, 78-83, 1996. https://doi.org/10.1128/ JVI.70.1.78-83.1996

Chalupny NJ, Rein-Weston A, Dosch S, Cosman D., Bioph. Res. Co. 346, 175-181, 2006. https://doi.org/10.1016/i. bbrc.2006.05.092

Chan AC, Carter PJ., Nat. Rev. Immunol.10,301-316,2010. https:// doi.org/10.1038/nri2761

Cheung TC, Humphreys IR, Potter KG, Norris PS, Shumway HM, Tran BR, Patterson G, Jean-Jacques R, Yoon M, Spear PG, Murphy KM, Lurain NS, Benedict CA, Ware CF., Proc. Natl.Acad.Sci.USA 102,13218-13223,2005. https:// doi.org/10.1073/pnas.0506172102

Chowdary TK, Cairns TM, Atanasiu D, Cohen GH, Eisenberg RJ, Heldwein EE., Nat. Struct. Mol. Biol. 17, 882-888, 2010. https://doi.org/10.1038/nsmb.1837

Compton T, Nepomuceno RR, Nowlin DM., Virology 191,387-395, 1992. https://doi.org/10.1016/0042-6822(92)90200-9

Cosman D, Müllberg J, Sutherland CL, Chin W, Armitage R, Fanslow W, Kubin M, Chalupny NJ., Immunity 14, 123133, 2001.https://doi.org/10.1016/S1074-7613(01)00095$\underline{4}$

Dargan DJ, Douglas E, Cunningham C, Jamieson F, Stanton RJ, Baluchova K, McSharry BP, Tomasec P, Emery VC, Percivalle E, Sarasini A, Gerna G, Wilkinson GW, Davison AJ., J. Gen. Virol. 91, 1535-1546, 2010. https:// doi.org/10.1099/vir.0.018994-0

Dasari V, Smith C, Khanna R., Expert Rev. Vaccines 12, 661-676, 2013. https://doi.org/10.1586/erv.13.46

Dassa L, Seidel E, Oiknine-Djian E, Yamin R, Wolf DG, Le-Trilling VTK, Mandelboim O., J. Virol. 92, e00162-18, 2018. https://doi.org/10.1128/JVI.00162-18

Delves PJ, Roitt IM, The Immune System. In Mackay I, Rosen FS (Eds): Advances in Immunology. Vol. 343, First of Two Parts. New England Journal of Medicine, Department of Immunology, the Windeyer Institute of Medical Sciences, University College London, London, Massachusetts Medical Society, pp. 37-49, 2000. https:// doi.org/10.1056/NEJM200007063430107

Diefenbach A, Chapter 4 - Natural Killer Cells. In Ackerman ME, Nimmerjahn F(Eds):Antibody Fc. Chapter 4. Academic Press, pp. 75-93, 2014. https://doi.org/10.1016/B978-012-394802-1.00004-2

Dolan A, Cunningham C, Hector RD, Hassan-Walker AF, Lee L, Addison C, Dargan DJ, McGeoch DJ, Gatherer D, Emery VC, Griffiths PD, Sinzger C, McSharry BP, Wilkinson GW, Davison AJ., J. Gen. Virol. 85, 1301-1312, 2004. https://doi.org/10.1099/vir.0.79888-0
Dollard SC, Grosse SD., Ross DS, Rev. Med. Virol.17,355-363, 2007. https://doi.org/10.1002/rmv.544

Dunn W, Chou C, Li H, Hai R, Patterson D, Stolc V, Zhu H, Liu F., Proc. Natl. Acad. Sci. USA 100, 14223-14228, 2003. https://doi.org/10.1073/pnas.2334032100

Eagle RA, Traherne JA, Hair JR, Jafferji I., Trowsdale J, Eur. J. Immunol.39,3207-3216,2009. https://doi.org/10.1002/ eji.200939502

Fielding CA, Weekes MP, Nobre LV, Ruckova E, Wilkie GS, Paulo JA, Chang C, Suárez NM, Davies JA, Antrobus R, Stanton RJ, Aicheler RJ, Nichols H, Vojtesek B, Trowsdale J, Davison AJ, Gygi SP, Tomasec P, Lehner PJ, Wilkinson GW., Elife 6, e22206, 2017. https://doi.org/10.7554/ eLife.22206

Fish KN, Soderberg-Naucler C, Mills LK, Stenglein S, Nelson JA., J. Virol. 72, 5661-5668, 1998. https://doi.org/10.1128/ JVI.72.7.5661-5668.1998

Fletcher JM, Prentice HG, Grundy JE., J. Immunol. 161, 23652374, 1998.

Fouts AE, Chan P, Stephan JP, Vandlen R, Feierbach B., J.Virol. 86, 7444-7447, 2012. https://doi.org/10.1128/JVI.00467-12

Fuchs A, Cella M, Giurisato E, Shaw AS, Colonna M., J. Immunol. 172, 3994-3998, 2004. https://doi.org/10.4049/jimmunol.172.7.3994

Gerna G, Percivalle E, Lilleri D, Lozza L, Fornara C, Hahn G, Baldanti F, Revello MG, J. Gen. Virol. 86, 275-284, 2005. https://doi.org/10.1099/vir.0.80474-0

Grundy JE, Downes KL., Immunology 78, 405-412, 1993. https:// doi.org/10.1097/00000542-199302000-00039

Hahn G, Revello MG, Patrone M, Percivalle E, Campanini G, Sarasini A, Wagner M, Gallina A, Milanesi G, Koszinowski U, Baldanti F, Gerna G., J. Virol. 78, 10023-10033, 2004. https://doi.org/10.1128/JVI.78.18.10023-10033.2004

Heldwein EE, Krummenacher C., Cell. Mol. Life. Sci. 65, 16531668, 2008. https://doi.org/10.1007/s00018-008-7570-z

Hsu JL, van den Boomen DJ, Tomasec P, Weekes MP, Antrobus R, Stanton RJ, Ruckova E, Sugrue D, Wilkie GS, Davison AJ, Wilkinson GW, Lehner PJ., PLoS Pathog. 11, e1004811, 2015. https://doi.org/10.1371/iournal. ppat.1004811

Huber MT, Compton T., J. Virol. 72, 8191-8197, 1998. https://doi org/10.1128/JVI.72.10.8191-8197.1998

Jarvis MA, Nelson JA., Curr. Opin. Microbiol. 5, 403-407, 2002 https://doi.org/10.1016/S1369-5274(02)00334-X

Jarvis MA, Nelson JA., J. Virol. 81, 2095-2101, 2007. https://doi. org/10.1128/JVI.01422-06

Kahl M, Siegel-Axel D, Stenglein S, Jahn G, Sinzger C., J. Virol. 74, 7628-7635, 2000. https://doi.org/10.1128/JVI.74.16.76287635.2000

Kaptein SJ, van Cleef KW, Gruijthuijsen YK, Beuken EV, van Buggenhout L, Beisser PS, Stassen FR, Bruggeman CA, Vink C., Virus Genes 29, 43-61, 2004. https://doi. org/10.1023/B:VIRU.0000032788.53592.7c

Kaye JF, Gompels UA, Minson AC., J. Gen. Virol. 73, 2693-2698, 1992. https://doi.org/10.1099/0022-1317-73-10-2693

Leitner J, Herndler-Brandstetter D, Zlabinger GJ, GrubeckLoebenstein B, Steinberger P., J. Immunol. 195, 477-487, 2015. https://doi.org/10.4049/jimmunol.1401917 
Li L, Nelson JA, Britt WJ., J.Virol.71,3090-3097,1997.https://doi. org/10.1128/JVI.71.4.3090-3097.1997

Lisnić B, Lisnić VJ, Jonjić S., Curr. Opin. Virol. 15, 9-18, 2015. https://doi.org/10.1016/i.coviro.2015.07.001

Loewendorf A, Benedict CA., J. Intern. Med. 267:483-501, 2010. https://doi.org/10.1111/j.1365-2796.2010.02220.x

Loomis RJ, Lilja AE, Monroe J, Balabanis KA, Brito LA, Palladino G, Franti M, Mandl CW, Barnett SW, Mason PW., Vaccine 31, 919-926, 2013. https://doi.org/10.1016/i. vaccine.2012.12.009

Lüttichau HR., J. Biol. Chem. 285, 9137-9146, 2010. https://doi. org/10.1074/jbc.M109.002774

Macagno A, Bernasconi NL, Vanzetta F, Dander E, Sarasini A, Revello MG, Gerna G, Sallusto F, Lanzavecchia A., J. Virol. 84, 1005-1013, 2009. https://doi.org/10.1128/ JVI.01809-09

Mach M, Kropff B, Dal Monte P, Britt W., J. Virol. 74, 1188111892, 2000. https://doi.org/10.1128/JVI.74.24.11881$\underline{11892.2000}$

Mahalingam D, Szegezdi E, Keane M, de Jong S, Samali A., Cancer Treat. Rev. 35, 280-288, 2009. https://doi.org/10.1016/j. ctrv.2008.11.006

Maier MK, Seth S, Czeloth N, Qiu Q, Ravens I, Kremmer E, Ebel M, Müller W, Pabst O, Förster R, Bernhardt G., Eur. J. Immunol. 37, 2214-2225, 2007. https://doi.org/10.1002/ eji.200737072

Malkowska M, Kokoszynska K, Dymecka M, Rychlewski L, Wyrwicz LS., Virol. J.10,1, 2013.https://doi.org/10.1186/1743422X-10-1

Marshall EE, Geballe AP., J. Interf. Cytok. Res. 29:609-619, 2009. https://doi.org/10.1089/jir.2009.0064

Matsuura H, Kirschner AN, Longnecker R, Jardetzky TS., Proc. Natl. Acad. Sci. USA 107, 22641-22646, 2010. https://doi. org/10.1073/pnas.1011806108

McSharry BP, Avdic S, Slobedman B., Viruses 4, 2448-2470, 2012. https://doi.org/10.3390/v4112448

Mocarski ES, Shenk T, Griffiths PD, Pass RF., Cytomegalovirus. In Knipe DM, Howley PM, Cohen JI, Griffin DE, Lamb RA, Martin MA, Racaniello VR, Roizman B(Eds): Fields Virology. Sixth edition. Vol.1. Philadelphia: Lippincott Williams \& Wilkins, pp. 1960-2014, 2013.

Murrell I, Wilkie GS, Davison AJ, Statkute E, Fielding CA, Tomasec P, Wilkinson GW, Stanton RJ., J. Virol. 90, 3929-3943, 2016. https://doi.org/10.1128/JVI.02858-15

Nemčovičová I, Benedict CA, Zajonc DM., PLoS Pathog. 9, e1003224, 2013. https://doi.org/10.1371/journal. ppat. 1003224

Nemčovičová I, Zajonc DM., Acta Crystallogr. D. 70, 851-862, 2014. https://doi.org/10.1107/S1399004713033750

Nguyen CC, Siddiquey MNA, Zhang H, Li G, Kamil JP., J. Virol. 92, e00688-18, 2018. https://doi.org/10.1128/JVI.00688-18

Nicholson LB, Essays Biochem. 60, 275-301, 2016. https://doi. org/10.1042/EBC20160017

Nogalski MT, Chan GC, Stevenson EV, Collins-McMillen DK, Yurochko AD., PLoS Pathog. 9, e1003463, 2013. https:// doi.org/10.1371/journal.ppat.1003463
Novak Z, Ross SA, Patro RK, Pati SK, Kumbla RA, Brice S, Boppana SB., J. Clin. Microbiol. 46, 882-886, 2008. https:// doi.org/10.1128/JCM.01079-07

Orange JS., J. Allergy Clin. Immun. 132, 515-526, 2013. https:// doi.org/10.1016/j.jaci.2013.07.020

Pan C, Zhu D, Wang Y, Li L, Li D, Liu F, Zhang CY, Zen K., PLoS Pathog. 12, e1006007, 2016. https://doi.org/10.1371/ journal.ppat.1006007

Patel M, Vlahava VM, Forbes SK, Fielding CA, Stanton RJ, Wang ECY., Front. Immunol. 9, 2214, 2018. https://doi. org/10.3389/fimmu.2018.02214

Patrone M, Secchi M, Fiorina L, Ierardi M, Milanesi G, Gallina A., J. Virol.79, 8361-8373, 2005. https://doi.org/10.1128/ JVI.79.13.8361-8373.2005

Picarda G, Benedict CA., J. Immunol. 200, 3881-3889, 2018. https://doi.org/10.4049/jimmunol.1800171

Poole E, Atkins E, Nakayama T, Yoshie O, Groves I, Alcami A, Sinclair J., J. Virol. 82, 4250-4256, 2008. https://doi. org/10.1128/JVI.02156-07

Poole E, King CA, Sinclair JH, Alcami A., EMBO J. 25, 4390-4399, 2006. https://doi.org/10.1038/sj.emboj.7601287

Pötzsch S, Spindler N, Wiegers AK, Fisch T, Rücker P, Sticht H, Grieb N, Baroti T, Weisel F, Stamminger T, Martin-Parras L, Mach M, Winkler TH., PLoS Pathog. 7, e1002172, 2011. https://doi.org/10.1371/journal.ppat.1002172

Prod'homme V, Sugrue DM, Stanton RJ, Nomoto A, Davies J, Rickards CR, Cochrane D, Moore M, Wilkinson GW, Tomasec P., J. Gen. Virol. 91, 2034-2039, 2010. https:// doi.org/10.1099/vir.0.021931-0

Rasmussen L, Matkin C, Spaete R, Pachl C, Merigan TC., J. Infect. Dis. 164, 835-842, 1991. https://doi.org/10.1093/ infdis/164.5.835

Revello MG, Zavattoni M, Furione M, Fabbri E, Gerna G., J. Infect. Dis. 193, 783-787,2006. https://doi.org/10.1086/500509

Rölle A, Halenius A, Ewen EM, Cerwenka A, Hengel H, Momburg F., Eur. J. Immunol. 46, 2420-2425, 2016. https://doi. org/10.1002/eji.201646492

Ryckman BJ, Jarvis MA, Drummond DD, Nelson JA, Johnson DC., J. Virol. 80, 710-722, 2006. https://doi.org/10.1128/ JVI.80.2.710-722.2006

Ryckman BJ, Rainish BL, Chase MC, Borton JA, Nelson JA, Jarvis MA, Johnson DC., J. Virol. 82, 60-70, 2008. https://doi. org/10.1128/JVI.01910-07

Schleiss MR., Curr. Top. Microbiol. 325, 361-382, 2008. https:// doi.org/10.1007/978-3-540-77349-8 20

Schuessler A, Sampaio KL, Scrivano L, Sinzger C., J. Virol. 84, 9019-9026, 2010. https://doi.org/10.1128/JVI.00572-10

Scrivano L, Sinzger C, Nitschko H, Koszinowski UH, Adler B., PLoS Pathog. 7, e1001256, 2011.https://doi.org/10.1371/ journal.ppat.1001256

Šedý JR, Balmert MO, Ware BC, Smith W, Nemčovičova I, Norris PS, Miller BR, Aivazian D, Ware CF., J. Biol. Chem. 292, 21060-21070, 2017. https://doi.org/10.1074/jbc. M117.813295

Šedý JR, Bjordahl RL, Bekiaris V, Macauley MG, Ware BC, Norris PS, Lurain NS, Benedict CA, Ware CF., J. Immunol. 191, 828-836, 2013. https://doi.org/10.4049/jimmu$\underline{n o l .1300894}$ 
Šedý JR, Spear PG, Ware CF., Nat. Rev. Immunol. 8, 861-873, 2008. https://doi.org/10.1038/nri2434

Siddiquey MNA, Zhang H, Nguyen CC, Domma AJ, Kamil JP., J. Virol. 92, e00896-18, 2018. https://doi.org/10.1128/ JVI.00896-18

Sijmons S, Thys K, Mbong Ngwese M, Van Damme E, Dvorak J, Van Loock M, Li G, Tachezy R, Busson L, Aerssens J, Van Ranst M, Maes P., J. Virol. 89, 7673-7695, 2015. https:// doi.org/10.1128/JVI.00578-15

Sinzger C, Grefte A, Plachter B, Gouw AS, The TH, Jahn G., J. Gen. Virol. 76, 741-750, 1995. https://doi.org/10.1099/00221317-76-4-741

Sinzger C, Kahl M, Laib K, Klingel K, Rieger P, Plachter B, Jahn G., J. Gen. Virol. 81, 3021-3035, 2000. https://doi. org/10.1099/0022-1317-81-12-3021

Sinzger C, Knapp J, Plachter B, Schmidt K, Jahn G., J. Virol. Methods 63, 103-112, 1997. https://doi.org/10.1016/ S0166-0934(97)02082-X

Smith MS, Bentz GL, Alexander JS, Yurochko AD., J. Virol. 78, 4444-4453,2004. https://doi.org/10.1128/JVI.78.9.44444453.2004

Smith MS, Bivins-Smith ER, Tilley AM, Bentz GL, Chan G, Minard J, Yurochko AD., J. Virol. 81, 7683-7694, 2007. https://doi. org/10.1128/JVI.02839-06

Smith W, Tomasec P, Aicheler R, Loewendorf A, Nemčovičová I, Wang EC, Stanton RJ, Macauley M, Norris P, Willen L, Ruckova E, Nomoto A, Schneider P, Hahn G, Zajonc DM, Ware CF, Wilkinson GW, Benedict CA., Cell Host Microbe 13, 324-335, 2013. https://doi.org/10.1016/i. chom.2013.02.003

Stanton RJ, Baluchova K, Dargan DJ, Cunningham C, Sheehy O, Seirafian S, McSharry BP, Neale ML, Davies JA, Tomasec P, Davison AJ, Wilkinson GW., J. Clin. Invest. 120, 3191-3208, 2010. https://doi.org/10.1172/JCI42955

Stanton RJ, Prod'homme V, Purbhoo MA, Moore M, Aicheler RJ, Heinzmann M, Bailer SM, Haas J, Antrobus R, Weekes MP, Lehner PJ, Vojtesek B, Miners KL, Man S, Wilkie GS, Davison AJ, Wang ECY, Tomasec P, Wilkinson GWG., Cell Host Microbe 16, 201-214, 2014. https://doi. org/10.1016/i.chom.2014.07.005

Takenawa T, Suetsugu S., Nat. Rev. Mol. Cell Bio. 8, 37-48, 2007. https://doi.org/10.1038/nrm2069

Thomas ML., Annu. Rev. Immunol. 7, 339-369, 1989. https://doi. org/10.1146/annurev.iy.07.040189.002011

Tomasec P, Wang EC, Davison AJ, Vojtesek B, Armstrong M, Griffin C, McSharry BP, Morris RJ, Liewellyn-Lacey S, Rickards C, Nomoto A, Sinzger C, Wilkinson GW., Nat. Immunol. 6, 181-188, 2005. https://doi.org/10.1038/ $\underline{\operatorname{ni} 1156}$
Urban M, Klein M, Britt WJ, Hassfurther E, Mach M., J. Gen. Virol.77,1537-1547,1996. https://doi.org/10.1099/00221317-77-7-1537

Urban M, Winkler T, Landini MP, Britt W, Mach M., J. Infect. Dis. 169, 83-90,1994. https://doi.org/10.1093/infdis/169.1.83

Vink C, Beisser PS, Bruggeman CA, Intervirology 42, 342-349, 1999. https://doi.org/10.1159/000053970

Vomaske J, Denton M, Kreklywich C, Andoh T, Osborn JM, Chen D, Messaoudi I, Orloff SL, Streblow DN., J. Virol. 86, 11833-11844, 2012. https://doi.org/10.1128/JVI.00452-12

Wang C, Zhang X, Bialek S, Cannon MJ., Clin. Infect. Dis. 52, e11e13, 2011a. https://doi.org/10.1093/cid/ciq085

Wang D, Li F, Freed DC, Finnefrock AC, Tang A, Grimes SN, Casimiro DR, Fu TM., Vaccine 29, 9075-9080, 2011b. https://doi.org/10.1016/i.vaccine.2011.09.056

Wang D, Shenk T., J. Virol. 79, 10330-10338, 2005a. https://doi. org/10.1128/JVI.79.16.10330-10338.2005

Wang D, Shenk T., Proc. Natl. Acad. Sci. USA 102, 18153-18158, 2005b. https://doi.org/10.1073/pnas.0509201102

Wang ECY, Pjechova M, Nightingale K, Vlahava VM, Patel M, Ruckova E, Forbes SK, Nobre L, Antrobus R, Roberts D, Fielding CA, Seirafian S, Davies J, Murrell I, Lau B, Wilkie GS, Suárez NM, Stanton RJ, Vojtesek B, Davison A, Lehner PJ, Weekes MP, Wilkinson GWG, Tomasec P., Pro. Natl. Acad. Sci. USA 115, 4998-5003, 2018. https:// doi.org/10.1073/pnas.1720950115

Ware CF., Sedý, Curr. Opin. Immunol. 23, 627-631, 2011. https:// doi.org/10.1016/j.coi.2011.08.008

Weekes MP, Tomasec P, Huttlin EL, Fielding CA, Nusinow D, Stanton RJ, Wang EC, Aicheler R, Murrell I, Wilkinson GW, Lehner PJ, Gygi SP., Cell 157,1460-1472,2014. https:// doi.org/10.1016/j.cell.2014.04.028

Weiner LM, Surana R, Wang S., Nat. Rev. Immunol. 10, 317-327, 2010. https://doi.org/10.1038/nri2744

Wen Y, Monroe J, Linton C, Archer J, Beard CW, Barnett SW, Palladino G, Mason PW, Carfi A, Lilja AE., Vaccine 32, 3796-3804, 2014. https://doi.org/10.1016/j.vaccine.2014.05.004

Wyrwicz LS, Rychlewski L., Antivir. Res. 75, 83-86,2007. https:// doi.org/10.1016/i.antiviral.2006.11.015

Yao S, Zhu Y, Chen L., Nat. Rev. Drug. Discov. 12, 130-146, 2013. https://doi.org/10.1038/nrd3877

Yoshie O, Matsushima K., Int. Immunol. 27, 11-20, 2015. https:// doi.org/10.1093/intimm/dxu079

Yu D, Silva MC, Shenk T., Proc. Natl. Acad. Sci. USA 100, 1239612401, 2003. https://doi.org/10.1073/pnas. 1635160100 Yurochko AD, Huang ES., J. Immunol. 162, 4806-4816, 1999. 